\title{
Tippers at island geomagnetic observatories constrain electrical conductivity of oceanic lithosphere and upper mantle
}

\author{
Achim Morschhauser ${ }^{1,2^{*}}$ (D) Alexander Grayver ${ }^{1}$, Alexey Kuvshinov ${ }^{1}$, Friedemann Samrock ${ }^{1}$ and Jürgen Matzka ${ }^{2}$
}

\begin{abstract}
Geomagnetic field variations as recorded at geomagnetic observatories are important for global electromagnetic studies. However, this data set is rarely used for studying the local electrical conductivity at depths $<200 \mathrm{~km}$. The main reasoning being that given a single geomagnetic observatory, one can at most constrain the one-dimensional (1-D) conductivity structure beneath it. At the same time, tippers, magnetic transfer functions resolving these depths, are zero for any 1-D conductivity distribution. We show that the ocean induction effect alleviates these limitations for observatories on islands and develop a method to invert tippers for a 1-D conductivity profile in the presence of three-dimensional conductivity structure due to bathymetry. This allows to recover 1-D upper mantle conductivity profiles at remote oceanic locations where little or no knowledge is available and that would otherwise be difficult to access. We apply the method to Gan in the Indian Ocean and to Tristan da Cunha in the South Atlantic, and the obtained conductivity profiles indicate a normal oceanic mantle and elevated conductivities, respectively, which fits well with their geological settings.
\end{abstract}

Keywords: Electrical conductivity, Tippers, Ocean effect, Tristan da Cunha, Maldives, Geomagnetic observatories, Oceanic upper mantle, Inversion

\section{Introduction}

More than 150 INTERMAGNET geomagnetic observatories around the world readily provide high-quality magnetic field data with a sampling rate of up to $1 \mathrm{~Hz}$ (St-Louis 2012). In principle, the recorded field variations with periods up to a few hours would allow to resolve the electrical conductivity distribution in the Earth's lithosphere and upper mantle. However, there are two limitations impeding such studies. First, geomagnetic observatories are sparse, hence for studies of the lithosphere and upper mantle only individual observatories can be considered. In consequence, one can at best resolve a one-dimensional (1-D) conductivity structure beneath specific locations. Second, the source of field variations under consideration is seen at mid-latitude

\footnotetext{
*Correspondence: achim.morschhauser@gfz-potsdam.de

${ }^{2}$ GFZ German Research Centre for Geosciences, 14473 Telegrafenberg,

Potsdam, Germany

Full list of author information is available at the end of the article
}

observatories as a time-varying vertically incident plane wave (Chave and Jones 2012). With such a source field, tippers are the only response functions that might be estimated from single observatories recording only geomagnetic data. However, tippers are zero for a purely 1-D conductivity distribution (Simpson and Bahr 2005; Berdichevsky and Dmitriev 2008), and therefore do not allow a meaningful interpretation with a single station.

Still, the situation is different for island and coastal observatories, where lateral conductivity contrasts between conductive sea water and more resistive island rock result in lateral conductivity variations and therefore large tipper amplitudes even if the underlying structure is essentially 1-D (Samrock and Kuvshinov 2013). This is referred to as the ocean (or coast) induction effect (Parkinson and Jones 1979). Berdichevsky and Dmitriev (2008) argued that tippers are also sensitive to vertical variations in conductivity. This was confirmed by Samrock and Kuvshinov (2013) using realistic three-dimensional (3-D) bathymetry and 1-D conductivity profiles that significantly differ within 
the lithosphere and upper mantle $(<200 \mathrm{~km})$. In their model study, the resulting variability in the modeled tippers exceeded the uncertainties in the observed tippers.

In this paper, we go a step further and develop a methodology to invert island tippers for a 1-D conductivity distribution in the presence of known 3-D bathymetry. Using this methodology, we first perform realistic synthetic tests and demonstrate that tippers from a single island observatory are indeed able to recover the synthetic 1-D conductivity profile. Then, we invert tippers obtained at two island observatories located in different tectonic environments, namely Gan (GAN) in the Indian Ocean and Tristan da Cunha (TDC) in the South Atlantic. Finally, we interpret the recovered 1-D profiles in terms of their regional geology and discuss the caveats of the 1-D assumption at remote oceanic islands.

\section{Methods}

\section{Tippers}

Tippers $\mathbf{T}$ are the only single-site geomagnetic response functions within the plane-wave paradigm. They relate the horizontal $\left(B_{x}, B_{y}\right)$ and the vertical $\left(B_{z}\right)$ magnetic field components as

$$
B_{z}(\omega)=\left(T_{z x}(\omega) T_{z y}(\omega)\right)\left(\begin{array}{l}
B_{x}(\omega) \\
B_{y}(\omega)
\end{array}\right) .
$$

Here $\omega=2 \pi / p$ is the angular frequency of geomagnetic field variations, where $p$ is a period, $z$ points positive downward, and $x$ and $y$ point to geographic North and East, respectively. As a consequence of the planewave excitation, variations in $B_{z}$ (and thus $\mathbf{T}$ ) are zero above 1-D conductivity structures (Simpson and Bahr 2005; Berdichevsky and Dmitriev 2008). Tippers are often represented in terms of real and imaginary induction arrows. In what follows, real induction arrows point away from conductive zones (Wiese convention, Wiese $1965)$ and are given by $\left(\mathfrak{R} T_{x}, \mathfrak{R} T_{y}\right)$. We estimated tippers from time-series of geomagnetic observatory data using robust processing methods (Appendix A). Additionally, univariate coherencies as well as multivariate coherencies were calculated, i.e., $\operatorname{coh}\left(T_{z x}\right)=\operatorname{corr}\left(B_{z}, T_{z x} B_{x}\right)$ and $\operatorname{coh}(\mathbf{T})=\operatorname{corr}\left(B_{z}, T_{z x} B_{x}+T_{z y} B_{y}\right)$, respectively. Here, corr refers to the Pearson correlation coefficient. In consequence, and as $B_{z}$ is a linear combination of $B_{x}$ and $B_{y}$ (Eq. 1), univariate coherencies $\operatorname{coh}\left(T_{z x}\right)$ and $\operatorname{coh}\left(T_{z y}\right)$ cannot simultaneously have values close to one. Note that this is also true for any univariate coherencies contributing to the same output variable (such as, for example, $\operatorname{coh}\left(Z_{x x}\right)$ and $\operatorname{coh}\left(Z_{x y}\right)$ for impedances).

\section{Numerical model}

As is shown in Fig. 1a, we parameterized the model by dividing the subsurface into $M$ "layers" with unknown homogeneous conductivities $\sigma_{i}$. Depending on bathymetry, these layers may not extend throughout the modeling domain and can be interrupted by regions of seawater conductivity. Further, conductivities of the air and sea remained fixed, and the sea conductivity values were obtained from the World Ocean Atlas (available as supplementary material in Grayver et al. 2016).

The conductivity contrast between rocks and saline seawater results in a complex 3-D conductivity structure. In order to model it accurately, a 3-D forward solver with adaptive mesh refinement is used that solves Maxwell's equations. The numerical mesh used for Tristan da Cunha is shown in Fig. 1b, and more details on the numerical scheme and solver can be found in Grayver and Kolev (2015) and in Appendix B.

\section{Synthetic test}

Samrock and Kuvshinov (2013) demonstrated that tippers are sensitive to different 1-D conductivity profiles in the presence of the ocean induction effect. Here, we perform synthetic tests to show that these differences are sufficient to infer the conductivity distribution with

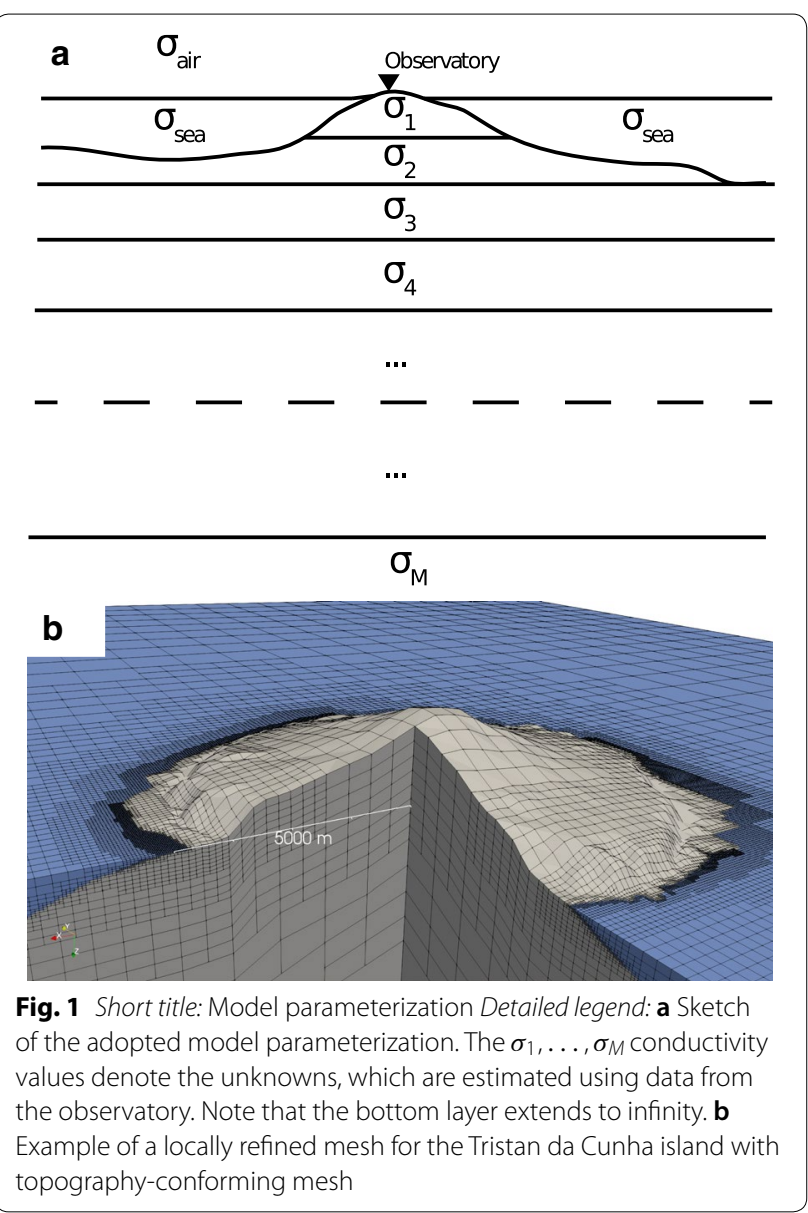


depth. For this purpose, we use the same bathymetry and numerical setup as for the real data from TDC (c.f. "Inversion of TDC data" section) and evaluate tippers at the location of the TDC observatory (see red diamond on inlet of Fig. 3b) for different profiles of electrical conductivity.

First, we illustrate the significance of the ocean induction effect by calculating tippers for a model with ocean plus a homogeneous Earth model (HOM) of $\rho=100$ $\Omega \mathrm{m}$ (dashed gray line in Fig. 2a). Without ocean induction effect, such a model would result in zero tippers. However, modeled tippers are significant as shown by dashed blue and red lines in Fig. 2b. Next, we choose a $1-\mathrm{D}$ conductivity profile that is varying with depth, as indicated by the red line in Fig. 2a. The crosses in Fig. 2b show the resulting tippers which differ significantly from those corresponding to the HOM. This result confirms that tippers are sensitive to the underlying 1-D conductivity structure, as has been shown by Samrock and Kuvshinov (2013). Next, we add 3 \% Gaussian noise to the synthetic tippers, as indicated by the error bars, and invert them for a 1-D conductivity profile. The synthetic tippers can be well fit (crosses and solid lines in Fig. 2b), and the obtained conductivity profile (black solid line in Fig. 2a) matches the true synthetic profile (red line) within its error limits (black dashed lines) as obtained from the diagonals of the model covariance matrix (i.e., only uncorrelated errors).

\section{Observed tippers}

Gan observatory (GAN)

The GAN geomagnetic observatory (Velimsky et al. 2014) is located on the Addu Atoll at the southern end of the Maldives archipelago, at $0.6946^{\circ} \mathrm{S}$ and $73.1537^{\circ} \mathrm{E}$ (red diamond in Fig. 3a). The Maldives archipelago consists of corals on top of the Maldive Ridge which was formed by the Réunion hot spot about 50-55 Ma ago (Fontaine et al. 2015, Fig. 1).

The top panel of Fig. 3c displays the observed induction arrows and the middle panel shows the real and imaginary parts of the corresponding tipper values. As expected, the real (blue) arrows point toward the more resistive island chain of the Maldives in the North (cf. Fig. 3a). Further, univariate coherencies (bottom panel) are significantly lower for $\operatorname{coh}\left(T_{z y}\right)$ than for $\operatorname{coh}\left(T_{z x}\right)$. This is due to the fact that both $\operatorname{coh}\left(T_{z y}\right)$ and $\operatorname{coh}\left(T_{z x}\right)$ cannot be simultaneously large ("Tippers" section), and that tippers are mainly oriented along the $\mathrm{S}-\mathrm{N}$ axis which results in a better signal-to-noise ratio for $T_{z x}$. Multivariate coherencies reach values $>0.8$ (black line), except for periods $<50 \mathrm{~s}$ where the sensitivity of the fluxgate magnetometer starts to decrease.

\section{Tristan da Cunha observatory (TDC)}

The TDC magnetic observatory (Matzka et al. 2009, 2010) is located on Tristan da Cunha island at $37.067^{\circ} \mathrm{S}$ and $12.315^{\circ} \mathrm{W}$ (red diamond on inlet of Fig. 3b) with

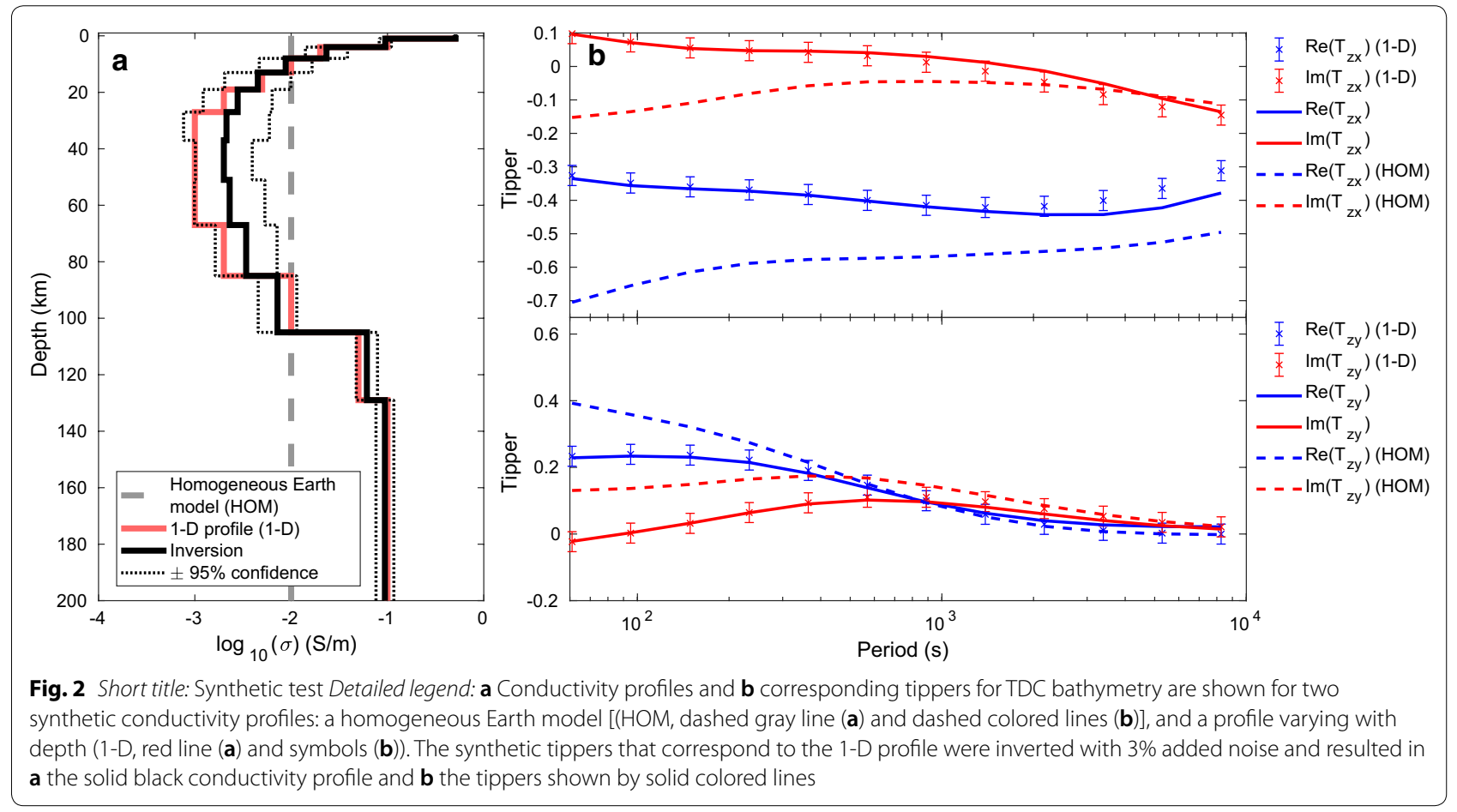


seafloor ages of 20-25 Myr (Müller et al. 2008). Tristan da Cunha is an active volcano in the South Atlantic Ocean, located at the western end of the Walvis Ridge that marks the Tristan-Gough hotspot track (Rohde et al. 2013)

The observed induction arrows, real and imaginary values of tippers, and coherencies are shown in Fig. 3d. As expected, the real arrows point toward the more resistive island of Tristan in the south-southeast (Fig. 3b), at least for periods up to $500 \mathrm{~s}$. For longer periods, they tend to be influenced by the presence of the islands Nightingale and Inaccessible to the south-southwest (Fig. 3b). Again, univariate coherencies are lower for $\operatorname{coh}\left(T_{z y}\right)$ than for $\operatorname{coh}\left(T_{z x}\right)$, especially at longer periods where tippers are almost perfectly aligned with the $\mathrm{S}-\mathrm{N}$ axis. Multivariate coherencies for tippers at TDC have values $>0.8$, except for periods $<20 \mathrm{~s}$. Compared to GAN, multivariate coherencies at short periods are higher as more data were available.

\section{Results and interpretation Inversion of GAN data}

The modeling domain covers an area of $936 \times 936 \mathrm{~km}$ with the GAN observatory at the center (Fig. 3a). Tippers were inverted for periods ranging between 40 and $10,000 \mathrm{~s}$, and a residual weighted RMS of 2.2 was achieved. The resulting best-fit tippers agree well with observed tippers, except for the real part of $T_{z y}$ (Fig. 4b). The poor fit to $T_{z y}$ may be related to the low coherency of $T_{z y}$ (c.f. Fig. 3c). Indeed, additional induction coil

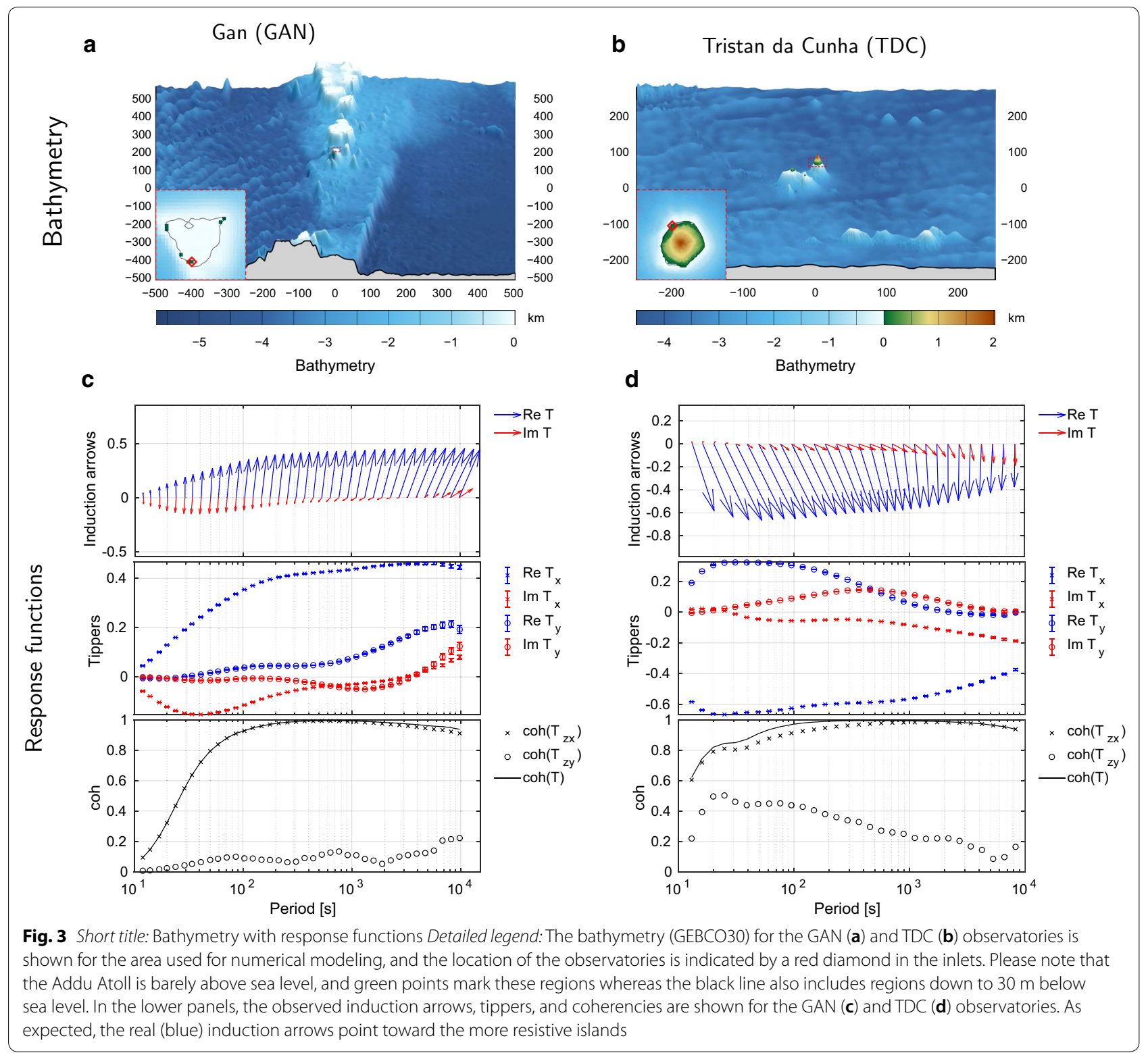


data, shown by crosses in Fig. 4b, show a better agreement with modeled tippers (solid lines). Alternatively, the misfit may result from 3-D conductivity structures that are incompatible with the assumed 1-D model, for example conductive seafloor sediments at some distance from the station, or from inaccuracies of the bathymetry model. Disregarding $T_{z y}$ slightly improves the fit to $T_{z x}$ without corrupting the fit to $T_{z y}$, as shown in Fig. $4 \mathrm{~b}$ by comparing the observed (open circles) and modeled (solid lines) tippers.

We validate the robustness of our model by additionally inverting $T_{z x}$ for a homogeneous Earth model (HOM), resulting in an electrical conductivity of $\sigma=24 \mathrm{mS} / \mathrm{m}$, and we note that an inversion to all the data results in a very similar conductivity of $\sigma=25 \mathrm{mS} / \mathrm{m}$. The model is shown by the gray dashed line in Fig. $4 \mathrm{a}$ and resembles

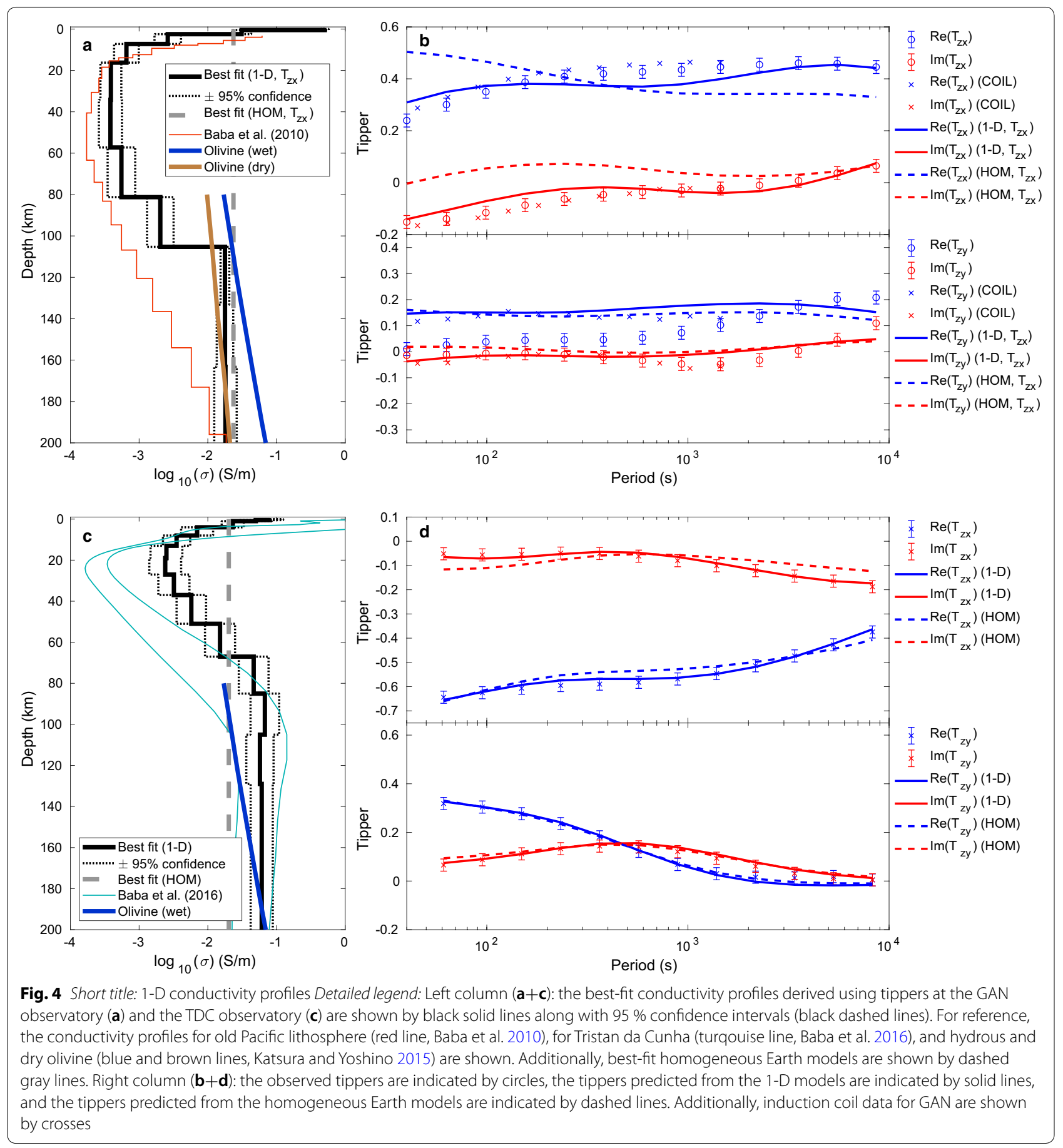


the conductivity of the 1-D model at depth. The corresponding tippers are shown by the dashed lines in Fig. 4b and fit the data with an RMS of 3.8 as compared to an RMS of 2.2 for the 1-D model. Clearly, the HOM Earth model is not able to reproduce all of the data. Therefore, additional variations in conductivity are required by the data, and here we assume that these additional variations are only depth dependent.

The conductivity model resulting from a fit to $T_{z x}$ only (black line in Fig. 4a) is characterized by a thin layer of conductive sediments, a thick layer of resistive crust and lithosphere, and a subsequent increase in conductivity with depth. Compared to the model resulting from a fit to all data, it is only slightly more resistive in the crust and lithosphere (not shown). Along with the model, the resulting 95\% confidence limits are provided, and we note that these depend on the data errors which in turn depend on the assumed error floor (see Appendix B).

The upper resistive layer probably characterizes volcanic and basement rock (Aubert and Droxler 1996), and the obtained upper mantle conductivity at depths $>110 \mathrm{~km}$ agrees with the conductivity of dry olivine (brown line in Fig. 4a) as calculated for a normal mantle geotherm with $T=1360^{\circ} \mathrm{C}$ at the lithosphere-asthenosphere boundary (Katsura and Yoshino 2015). For comparison, the corresponding conductivity of wet olivine is shown by the blue line (Katsura and Yoshino 2015). Overall, the recovered 1-D conductivity profile resembles the conductivity of resistive 125-150 Myr old Pacific upper mantle (Baba et al. (2010), red line in Fig. 4a), and differences at depths of $110-170 \mathrm{~km}$ possibly result from lower sensitivity at these depths and smoothing regularization that penalizes any structure. In conclusion, our model suggests no thermal or compositional anomalies at the base of the lithosphere of the Maldives Ridge, in agreement with seismic tomography data (Fontaine et al. 2015).

\section{Inversion of TDC data}

TDC has less prominent regional bathymetry as compared to GAN (Fig. 3b), and therefore a numerical domain of $586 \times 586 \mathrm{~km}$ was sufficient. Further, tippers were modeled for periods between 60 and $8264 \mathrm{~s}$, and an overall residual weighted RMS of 0.5 was achieved. The resulting conductivity profile is shown along with its confidence limits by the black solid and dashed lines in Fig. 4c, and the corresponding modeled and observed tippers are shown by the solid line and symbols in Fig. 4d. The model fits the data very well, and only the longest periods of $\operatorname{Re}\left(T_{z y}\right)$ are not entirely fit within their error limits.

Similar as for GAN, we validate the robustness of our model by additionally inverting for a homogeneous Earth model (HOM). The obtained electrical conductivity of $\sigma=20 \mathrm{mS} / \mathrm{m}$ roughly corresponds to the average conductivity of the 1-D model. The corresponding tippers fit the data with an RMS of 1.1 as compared to an RMS of 0.5 for the 1-D model and are shown by the dashed lines in Fig. 4d. As for GAN, the HOM Earth model is not able to fit all of the data, especially for $T_{z x}$.

Compared to GAN, conductivities are overall higher for TDC with a thinner resistive layer followed by a increase in conductivity that starts at $\approx 30 \mathrm{~km}$ depth. As for GAN, the conductivity of hydrous olivine (Katsura and Yoshino 2015) is shown by the blue line in Fig. 4c. In comparison with the obtained conductivities and their confidence interval, the presence of melt is therefore not required at depth, although it cannot be excluded either. In addition, the 3-D envelope of a recent 3-D MT seabottom survey by Baba et al. (2016) is shown by the turquoise lines in Fig. 4c. Baba et al. (2016) concluded that no plume-like structure below the island is necessary to explain the data, but the authors note that their survey layout would not sense small-scale $(<150 \mathrm{~km})$ structures directly below the island due to the absence of measurements in the island's vicinity. Other studies found indications for melt below TDC. For example, Weit et al. (2017) concluded from geochemical considerations that melt fractions of $5 \%$ are present at depths of $60-100 \mathrm{~km}$. Also, seismic tomography suggests a crustal low-velocity anomaly characteristic for a magma feeding system below the island (Ryberg et al. 2017).

Overall, the electrical conductivities obtained by Baba et al. (2016) agree well with this study, with the exception of a more resistive crust and lithosphere, especially at depths of $20-50 \mathrm{~km}$. This confirms the validity of our approach, and the potential to resolve 1-D conductivity profiles using tippers and geomagnetic observatory data. Still, we note that results should not be overinterpreted, as the presented approach is only useful if the $1-\mathrm{D}$ conductivity assumption is not strongly violated, and if the used model of bathymetry is of good quality and resolution.

\section{Discussion and conclusions}

To our knowledge, tippers estimated at geomagnetic observatories have not been used for studying 1-D electrical conductivity distributions. However, tippers dominated by 3-D effects such as bathymetry also contain information on the vertical conductivity profile (Berdichevsky and Dmitriev 2008; Samrock and Kuvshinov 2013). In consequence, if the 3-D effects are known, the 1-D conductivity profile can be extracted.

Here, we demonstrated with synthetic tests that tippers can be used to resolve the 1-D conductivity 
structure below islands where 3-D effects are constrained by bathymetry. Further, we processed geomagnetic data from two island observatories, Gan in the Indian Ocean and Tristan da Cunha in the South Atlantic, to estimate and invert tippers. The obtained electrical conductivity profile beneath Gan island exhibits no anomalous behavior and is in agreement with other results for old oceanic upper mantle. For TDC, electrical conductivities are higher than for GAN, which may be explained by increased temperatures or increased water content. The presence of melt below the island is not required by the data, but cannot be excluded either. In the same area, an extensive 3-D MT sea-bottom survey (Baba et al. 2016) obtained electrical conductivities that are very similar to our results, confirming the applicability of the proposed method. Additionally, we test the robustness of the obtained 1-D profiles by inverting for a homogeneous Earth model and conclude that the additional 1-D variability is required by the data.

We note that our approach relies on the assumption that no additional 3-D conductivity anomalies are present. In consequence, any such anomalies may lead to misleading results, or to the unability of the model to fit the data. Clearly, remote and active volcanic islands are anomalous regions, for example due to hotspot mantle plumes. Still, the developed methodology allows us to obtain knowledge of the oceanic lithosphere and upper mantle from available single-site geomagnetic observatory data that otherwise cannot be used for induction studies. Therefore, as long as we are aware of its limitations, the method will help to better understand the oceanic lithosphere and upper mantle in remote regions where otherwise little or no knowledge is available. Furthermore, when combined with longer period responses due to $\mathrm{Sq}$ or magnetospheric sources, this methodology provides a unique opportunity for imaging the electrical structure of the mantle throughout its full depth range. In future, more complete 3-D studies with multiple magnetometers or additional measurements of field intensity (Kuvshinov et al. 2016) are also feasible.

\footnotetext{
Abbreviations

TDC: Tristan da Cunha observatory; GAN: Gan observatory; 1-D: one-dimensional; 3-D: three-dimensional; HOM: homogeneous Earth model; RMS: root mean square (of residuals); GEBCO: General Bathymetry Chart of the Oceans.

\section{Author's contributions}

AM processed and analyzed the magnetic field data, AG performed the inversions and synthetic tests, AK created the concept of the study, and FS and JM obtained and provided information on the GAN and TDC magnetic field data, respectively. AM drafted the manuscript. All authors read and approved the final manuscript.
}

\begin{abstract}
Author details
${ }_{1}^{1}$ Institute of Geophysics, ETH Zürich, Zürich, Switzerland. ${ }^{2}$ GFZ German Research Centre for Geosciences, 14473 Telegrafenberg, Potsdam, Germany.

\section{Acknowledgements}

The reviews by Paul A. Bedrosian and one anonymous reviewer greatly helped to improve this manuscript. We thank ETH Zürich, the Gan Meteorological Office, and GFZ Potsdam for supporting the operation of the observatories GAN and TDC, and INTERMAGNET for promoting high standards of magnetic observatory practice (www.intermagnet.org). We gratefully acknowledge the work of Ahmed Muslim who locally operates the GAN observatory and Robin Repetto who locally operates the Tristan da Cunha observatory. Without their help and enthusiasm, this work wouldn't have been possible. Also, we acknowledge the work of the GEBCO group and are grateful for using their data ('The GEBCO_2014 Grid, version 20150318, www.gebco.net'). As well, we are grateful for using the ASTER GDEM data (ASTER GDEM is a product of METI and NASA). Finally, we thank Wessel and Smith (1998) for sharing their Generic Mapping Tools (GMT).
\end{abstract}

\section{Availability of data and materials}

The results presented in this paper rely on $1 \mathrm{~Hz}$ data collected at TDC and GAN geomagnetic observatories. These data were digitally filtered to produce one minute means that are available from the INTERMAGNET data repository.

\section{Competing interests}

The authors declare that they have no competing interests.

\section{Funding}

This work was supported by a Grant from the Swiss National Supercomputing Centre (CSCS) under Project ID767. The research stay of AM at ETH Zürich was funded by DFG ("Deutsche Forschungsgemeinschaft") under Grant No. MO2598/1-1.

\section{Appendix A: Data processing}

The GAN geomagnetic observatory was installed in April 2011 in the area of the GAN International Airport, and accepted as an INTERMAGNET observatory in October 2013. The observatory is operated by ETH Zürich and Gan Meteorological Office (Velimsky et al. 2014). Vector magnetic field variations are recorded by a DTU Fluxgate magnetometer (Pedersen and Merenyi 2016) at a sampling rate of $1 \mathrm{~Hz}$. These data are digitally filtered to produce one minute means and subsequently calibrated for publication at INTERMAGNET. In this study, we use unpublished $1 \mathrm{~Hz}$ data which we calibrate and rotate to geographic coordinates using the available observatory baselines.

The Tristan da Cunha geomagnetic observatory is operated by GFZ Potsdam and was established in October 2009. Since 2012, it is part of the INTERMAGNET network of observatories. Similar to GAN, $1 \mathrm{~Hz}$ vector magnetic field data are recorded by a DTU fluxgate magnetometer (Pedersen and Merenyi 2016), and calibrated and digitally filtered minute means are available on INTERMAGNET. For more details, the reader is referred to Matzka et al. $(2009,2010)$. Similar to GAN, we use unpublished $1 \mathrm{~Hz}$ data which we calibrate and rotate to geographic coordinates using the available observatory baselines. 
Prior to the estimation of tippers, obvious spikes were manually removed from the selected time-series data. Then, for each discrete frequency $\omega_{i}$, data were split into overlapping and tapered windows of two period lengths before the data in each window were transformed to spectral domain. Subsequently, tippers were obtained using robust linear regression based on the Huber norm (e.g., Farquharson and Oldenburg 1998; Püthe and Kuvshinov 2014). The quality of the obtained transfer functions was evaluated by estimating confidence intervals $\delta_{i}$ for each frequency $\omega_{i}$ from linear propagation of data noise (Draper and Smith 1998), and data noise was estimated from the residuals. However, it should be noted that this approach often underestimates real uncertainties (Egbert and Booker 1986).

\section{Appendix B: Numerical model}

The presence of the ocean requires to solve Maxwell's equations for a given 3-D conductivity distribution. To this end, we solved

$$
\begin{aligned}
& \nabla \times\left(\mu_{0}^{-1} \nabla \times \mathbf{E}\right)+i \omega \sigma \mathbf{E}=0 \quad \text { in } \quad \Omega \\
& \mathbf{E}=\mathbf{E}_{0} \text { on } \partial \Omega
\end{aligned}
$$

for the complex-valued electric field vector E. Here, $\Omega \subseteq \mathbb{R}^{3}$ is the modeling domain, $\mu_{0}$ the magnetic permeability of free space, and $\sigma$ denotes the real-valued 3-D electric conductivity. Further, we applied the inhomogeneous Dirichlet boundary conditions, and $\mathbf{E}_{0}$ resulted from the solution of Maxwell's equations on the boundaries. We discretized Eq. (2) using the finite-element method on a non-conforming hexahedral mesh. Finally, the corresponding magnetic fields were calculated by virtue of Faraday's law. For more details on the underlying numerical scheme and solver, the reader is referred to Grayver and Kolev (2015).

The corresponding numerical mesh was adapted to the regional bathymetry that was obtained from the General Bathymetry Chart of the Oceans (GEBCO). This dataset provides a global bathymetry map at a resolution of $30^{\prime \prime}$ that has been compiled from a variety of sources (Weatherall et al. 2015), including the land topography dataset SRTM30 at the same resolution (Farr et al. 2007). The mesh was refined at the seafloor and along the coastlines, as well as close to the observatory. For Tristan da Cunha, additional ASTER topography data with a resolution of $30 \mathrm{~m}$ have been included due to strong topographic gradients (NASA et al. 2001). For GAN, the minimal cell size of the locally refined mesh is $62.5 \times 62.5 \times 15.6 \mathrm{~m}$ $(x \times y \times z)$.

In order to invert the observed tippers $\mathbf{d} \in \mathbb{R}^{N}$ for the model parameters $\mathbf{m} \in \mathbb{R}^{M}$, we minimized the regularized functional

$$
\underset{\mathbf{m}}{\operatorname{argmin}} \frac{1}{2}\left(\sum_{i=1}^{N}\left|w_{i}\left(f_{i}(\mathbf{m})-d_{i}\right)\right|^{2}+\frac{\beta}{p} \sum_{i=1}^{M}\left|\mathbf{l}_{i} \mathbf{m}\right|^{p}\right),
$$

where $w_{i}$ are the data weights, $f_{i}$ represents the forward operator obtained from solving Eq. $2, \beta$ is a regularization parameter, $\mathbf{l}_{i}$ is a regularization operator for the $i$ th model parameter penalizing model parameter jumps, and scalar $p$ controls the norm of the regularization term. The data weights $w_{i}$ were defined from the estimated confidence intervals $\delta_{i}$ and an absolute error floor $e_{i}=0.025$ such that $w_{i}=1 / \max \left(e_{i}, \delta_{i}\right)$. Please note that the level of error floor is quite arbitrary, but the resulting $R M S$ of the residuals should in principle approach one under the assumption of Gaussian noise. The unknown model parameters were given by $\mathbf{m}=\left[\lambda\left(\sigma_{1}\right) \cdots \lambda\left(\sigma_{M}\right)\right]$, where $\lambda(\cdot)$ represents a log-based transformation used to bound parameters (Key 2016). Here, $\sigma_{i}$ denote the 1-D conductivity profile of the subsurface that was divided into $M=11$ "layers" of increasing thickness (from $0.5 \mathrm{~km}$ at the top to $30 \mathrm{~km}$ at the bottom) and with homogeneous conductivities.

The minimization problem (3) was solved using a stochastic optimization method called Covariance Matrix Adaptation Evolution Strategy (CMAES, Hansen and Ostermeier 2001). This method is capable to reach global minima and is independent of the starting model. It permits usage of other than $L_{2}$-norm metrics, and supplies information on model uncertainty. Here, we used $p=1.5$ (Grayver and Kuvshinov 2016), and the regularization parameter $\beta$ was chosen using the discrepancy principle (Farquharson and Oldenburg 2004).

\section{Publisher's Note}

Springer Nature remains neutral with regard to jurisdictional claims in published maps and institutional affiliations.

Received: 6 September 2018 Accepted: 22 January 2019 Published online: 13 February 2019

\section{References}

Aubert O, Droxler A (1996) Seismic stratigraphy and depositional signatures of the maldive carbonate system (Indian Ocean). Mar Pet Geol 13(5):503536. https://doi.org/10.1016/0264-8172(96)00008-6

Baba K, Utada H, Goto T, Kasaya T, Shimizu H, Tada N (2010) Electrical conductivity imaging of the philippine sea upper mantle using seafloor magnetotelluric data. Phys Earth Planet Int 183(1-2):44-62. https://doi. org/10.1016/j.pepi.2010.09.010

Baba K, Chen J, Sommer M, Utada H, Geissler WH, Jokat W, Jegen M (2016) Marine magnetotellurics imaged no distinct plume beneath the Tristan da Cunha hotspot in the southern Atlantic ocean. Tectonophysics 716:52-63. https://doi.org/10.1016/j.tecto.2016.09.033

Berdichevsky M, Dmitriev VI (2008) Models and methods of magnetotellurics. Springer, Berlin. https://doi.org/10.1007/978-3-540-77814-1

Chave AD, Jones AG (2012) Introduction to the magnetotelluric method. In: Chave AD, Jones AG (eds) The magnetotelluric method. Cambridge 
University Press, Cambridge, pp 1-18. https://doi.org/10.1017/cbo97 81139020138.002 (chap 1)

Draper NR, Smith H (1998) Applied regression analysis, 3rd edn. Wiley, New York. https://doi.org/10.1002/9781118625590

Egbert GD, Booker JR (1986) Robust estimation of geomagnetic transfer functions. Geophys J Int 87(1):173-194. https://doi.org/10.1111/j.1365246X.1986.tb04552.x

Farquharson CG, Oldenburg DW (1998) Non-linear inversion using general measures of data misfit and model structure. Geophys J Int 134:213-227. https://doi.org/10.1046/j.1365-246X.1998.00555.x

Farquharson CG, Oldenburg DW (2004) A comparison of automatic techniques for estimating the regularization parameter in non-linear inverse problems. Geophys J Int 156(3):411-425. https://doi.org/10.1111/j.1365246x.2004.02190.x

Farr TG, Rosen PA, Caro E, Crippen R, Duren R, Hensley S, Kobrick M, Paller M, Rodriguez E, Roth L, Seal D, Shaffer S, Shimada J, Umland J, Werner M, Oskin M, Burbank D, Alsdorf D (2007) The shuttle radar topography mission. Rev Geophys 45(2):RG2004. https://doi.org/10.1029/2005RG000183

Fontaine FR, Barruol G, Tkalčić H, Wlbern I, Rmpker G, Bodin T, Haugmard M (2015) Crustal and uppermost mantle structure variation beneath la Réunion hotspot track. Geophys J Int 203(1):107-126. https://doi. org/10.1093/gji/ggv279

Grayver AV, Kolev TV (2015) Large-scale 3D geoelectromagnetic modeling using parallel adaptive high-order finite element method. Geophysics 80(6):E277-E291. https://doi.org/10.1190/geo2015-0013.1

Grayver AV, Kuvshinov AV (2016) Exploring equivalence domain in nonlinear inverse problems using covariance matrix adaption evolution strategy (CMAES) and random sampling. Geophys J Int 205(2):971-987. https:// doi.org/10.1093/gji/ggw063

Grayver AV, Schnepf NR, Kuvshinov AV, Sabaka TJ, Manoj C, Olsen N (2016) Satellite tidal magnetic signals constrain oceanic lithosphere-asthenosphere boundary. Sci Adv 2(9):e1600798. https://doi.org/10.1126/sciadv.1600798

Hansen N, Ostermeier A (2001) Completely derandomized self-adaptation in evolution strategies. Evol Comput 9(2):159-195. https://doi. org/10.1162/106365601750190398

Katsura T, Yoshino T (2015) The earths heterogenous mantle, chap heterogeneity of electrical conductivity in the Oceanic upper mantle. Springer Geophysics, Cham, pp 173-204. https://doi.org/10.1007/978-3-319-15627 $-9 \_6$

Key K (2016) MARE2DEM: a 2-D inversion code for controlled-source electromagnetic and magnetotelluric data. Geophys J Int 207(1):571-588. https ://doi.org/10.1093/gji/ggw290

Kuvshinov A, Matzka J, Poedjono B, Samrock F, Olsen PS (2016) Probing Earth's conductivity structure beneath oceans by scalar geomagnetic data: autonomous surface vehicle solution. Earth Planets Space 68(1):189. https://doi.org/10.1186/s40623-016-0553-7

Matzka J, Olsen N, Maule CF, Pedersen LW, Berarducci AM, Macmillan S (2009) Geomagnetic observations on Tristan da Cunha, South Atlantic ocean. Ann Geophys Italy 52:97-105. https://doi.org/10.4401/ag-4633
Matzka J, Chulliat A, Mandea M, Finlay CC, Qamili E (2010) Geomagnetic observations for main field studies: from ground to space. Space Sci Rev 155:29-64. https://doi.org/10.1007/s11214-010-9693-4

Müller RD, Sdrolias M, Gaina C, Roest WR (2008) Age, spreading rates, and spreading asymmetry of the world's ocean crust. Geochem Geophys Geosyst https://doi.org/10.1029/2007GC001743

NASA, METI, AIST, Japan Spacesystems, US/Japan ASTER Science Team (2001) ASTER global digital elevation model (GDEM) v2. https://doi.org/10.5067/ aster/ast14dem.003. NASA EOSDIS Land Processes DAAC

Parkinson WD, Jones FW (1979) The geomagnetic coast effect. Rev Geophys 17(8):1999-2015. https://doi.org/10.1029/rg017i008p01999

Pedersen LW, Merenyi L (2016) The FGE magnetometer and the INTERMAGNET 1 second standard. J Ind Geophys Union 2:30-36

Püthe C, Kuvshinov A (2014) Mapping 3-D mantle electrical conductivity from space: a new 3-D inversion scheme based on analysis of matrix Q-responses. Geophys J Int 197(2):768-784. https://doi.org/10.1093/gji/ ggu027

Rohde JK, van den Bogaard P, Hoernle K, Hauff F, Werner R (2013) Evidence for an age progression along the tristan-gough volcanic track from new 40ar/39ar ages on phenocryst phases. Tectonophysics 604:60-71. https:// doi.org/10.1016/j.tecto.2012.08.026

Ryberg T, Geissler WH, Jokat W, Pandey S (2017) Uppermost mantle and crustal structure at Tristan da Cunha derived from ambient seismic noise. Earth Planet Sci Lett 471:117-124. https://doi.org/10.1016/j.epsl.2017.04.049

Samrock F, Kuvshinov A (2013) Tippers at island observatories: Can we use them to probe electrical conductivity of the Earth's crust and upper mantle? Geophys Res Lett 40:824-828. https://doi.org/10.1002/grl.50218

Simpson F, Bahr K (2005) Practical magnetotellurics. Cambridge University Press, Cambridge. https://doi.org/10.1017/CBO9780511614095y St-Louis B (ed) (2012) Technical reference manual. 4.6, INTERMAGNET Velimsky J, Muslim A, Ziyad I, Jackson A, Kuvshinov A, Samrock F, Arora K, Rao K, Pedersen LW, Finlay C, Riddick J (2014) Geomagnetic observatory Gan. In: Abstracts of XVI IAGA workshop on geomagnetic observatory instruments, data acquisition and processing

Weatherall P, Marks KM, Jakobsson M, Schmitt T, Tani S, Arndt JE, Rovere M, Chayes D, Ferrini V, Wigley R (2015) A new digital bathymetric model of the world's oceans. Earth Space Sci 2(8):331-345. https://doi. org/10.1002/2015ea000107

Weit A, Trumbull RB, Keiding JK, Geissler WH, Gibson SA, Veksler IV (2017) The magmatic system beneath the Tristan da Cunha island: insights from thermobarometry, melting models and geophysics. Tectonophysics 716:64-76. https://doi.org/10.1016/j.tecto.2016.08.010

Wessel P, Smith WHF (1998) New improved version of the generic mapping tools released. EOS Trans Am Geophys Union 79:579. https://doi. org/10.1029/98EO00426

Wiese H (1965) Geomagnetische Induktionspfeile in der ČSSR, Hervorgerufen durch Grossräumige Elektrische Leitfähigkeitsstrukturen. Stud Geophys Geod 9:415-419. https://doi.org/10.1007/BF02607678

\section{Submit your manuscript to a SpringerOpen ${ }^{\circ}$ journal and benefit from:}

- Convenient online submission

- Rigorous peer review

- Open access: articles freely available online

- High visibility within the field

- Retaining the copyright to your article

Submit your next manuscript at $\boldsymbol{\nabla}$ springeropen.com 